\title{
Optical and thermal characteristics of glasses based on $\mathrm{TeO}_{2}$
}

\author{
EL SAYED YOUSEF ${ }^{1,2 *}$, A E AL-SALAMI ${ }^{1}$ and MARIO HOTZEL ${ }^{3}$ \\ ${ }^{1}$ Physics Department, Faculty of Science, King Khalid University, P.O. Box 9004, Abha, Saudi Arabia \\ ${ }^{2}$ Physics Department, Faculty of Science, Al-Azhar University, Assiut, Egypt \\ ${ }^{3}$ Institut für Optik und Quantenelektronik, Jena University, Jena, Germany
}

MS received 17 October 2011; revised 16 February 2012

\begin{abstract}
Glass samples have been synthesized in quaternary system based on $\mathrm{TeO}_{2}-\mathrm{oxide}$ within composition, $85 \mathrm{TeO}_{2}-5 \mathrm{Nb}_{2} \mathrm{O}_{5}-5 \mathrm{ZnO}-5 \mathrm{Ag}_{2} \mathrm{O}, 68 \mathrm{TeO}_{2}-5 \mathrm{Nb}_{2} \mathrm{O}_{5}-20 \mathrm{ZnO}-7 \mathrm{Na}_{2} \mathrm{O}$ and $\left[(75-x) \mathrm{TeO}_{2}-5 \mathrm{Nb}_{2} \mathrm{O}_{5}-20 \mathrm{ZnO}-x \mathrm{PbO}, x=7\right.$, $18 \mathrm{~mol} \%$ ]. Structural characterization of the glasses was studied with respect to their thermal stability, refractive indices, third order nonlinear optical susceptibility, IR spectra and Vickers hardness. For four different prepared glasses, density in the range from 5.3744 to $6.0731 \mathrm{~g} \cdot \mathrm{cm}^{-1}$, the glass transition temperature $\left(T_{\mathrm{g}}\right)$ in the range from 326 to $350{ }^{\circ} \mathrm{C}$ and refractive indices, $n$, in the range from $2 \cdot 1273$ to 2.2123 at $435 \mathrm{~nm}$ and Vickers hardness, $H_{\mathrm{v}}$, in the range from 2.91 to 3.44 GPa were determined. The value of third order nonlinear optical susceptibilities $\left|\chi^{(3)}\right| \approx$ $17.9 \cdot 10^{-13}$ esu of glass within composition, $68 \mathrm{TeO}_{2}-5 \mathrm{Nb}_{2} \mathrm{O}_{5}-20 \mathrm{ZnO}-7 \mathrm{PbO}$, was measured by using degenerate four-wave mixing (DFWM).
\end{abstract}

Keywords. Oxide glasses; linear and nonlinear refractive index; thermal stability; IR.

\section{Introduction}

$\mathrm{TeO}_{2}$-based glasses were frequently studied due to their high potential in optical communication systems. Moreover to having an excellent optical nonlinearity, it had good optical switching optical response, low optical loss, excellent chemical durability and thermal stability (Kim and Yoko 1995; Hoppe et al 2002; Narayanan and Zwanziger 2003). These properties due to high polarizability of $\mathrm{Te}^{4+}$ ions can be even more enhanced by means of incorporation of other heavy metal oxides that can be easily polarized (e.g. $\left.\mathrm{Pb}^{2+}, \mathrm{Bi}^{3+}\right)$ and with empty $d$ orbital $\left(\mathrm{Ti}^{4+}, \mathrm{Nb}^{5+}\right)$. It was reported that such additions lead to remarkable changes in the physical, especially the optical properties (Hoppe et al 2004). Hence, these glasses are regarded as promising optical materials for up conversion lasers and nonlinear optical materials, which exhibit high third order nonlinear optical susceptibilities (Yousef et al 2004, 2007). It is well known that the unit structures of $\mathrm{TeO}_{2}$ crystal is positioned in $\left[\mathrm{TeO}_{4 / 2}\right]^{0}$ which has a trigonal bipyramidal (tbp) and $\left[\mathrm{TeO}_{3 / 2}\right]^{0}$ which has a trigonal pyramidal (tp) structure. Trigonal pyramidal units form chains while $\left[\mathrm{TeO}_{4 / 2}\right]^{0}$ tbp units lead to three dimensional structures. Tellurite glasses in the systems such as $\mathrm{TeO}_{2}-\mathrm{Nb}_{2} \mathrm{O}_{3}, \mathrm{TeO}_{2}-\mathrm{ZnO}$ and $\mathrm{TeO}_{2}-$ $\mathrm{Nb}_{2} \mathrm{O}_{5}-\mathrm{PbO}$ have demonstrated to have excellent nonlinear optical performance (Komatsu et al 1994). The structure and nonlinear optical performance of $\mathrm{TeO}_{2} / \mathrm{Nb}_{2} \mathrm{O}_{5} / \mathrm{ZnO}$ glasses have been studied. These glasses had high nonlinear optical response time due to the deformation of electron clouds, such an ultra fast nonlinear optical response

\footnotetext{
*Author for correspondence (omn_yousef2000@yahoo.com)
}

makes these $\mathrm{TeO}_{2} / \mathrm{Nb}_{2} \mathrm{O}_{5} / \mathrm{ZnO}$ glasses highly suitable for all optic switching applications (Lin et al 2004). The value of third order nonlinear optical susceptibility of $\mathrm{TeO}_{2} /$ $\mathrm{Nb}_{2} \mathrm{O}_{5} / \mathrm{ZnO}$ with additive $\mathrm{CdS}$ glasses was found up to $7 \cdot 8 \times$ $10^{-13}$ esu, which indicates that these glasses can be used for optoelectronic application (Yousef et al 2008). Hence, in this work we investigated thermal and nonlinear optical properties of $\mathrm{TeO}_{2}-\mathrm{Nb}_{2} \mathrm{O}_{5}-\mathrm{ZnO}$ ternary glasses with added $\mathrm{Ag}_{2} \mathrm{O}, \mathrm{PbO}$ and $\mathrm{Na}_{2} \mathrm{O}$. This work may be of importance in the design of nonlinear devices of the prepared glasses.

\section{Experimental}

Glasses with composition $\left(85 \mathrm{TeO}_{2}-5 \mathrm{Nb}_{2} \mathrm{O}_{5}-5 \mathrm{ZnO}-\right.$ $\left.5 \mathrm{Ag}_{2} \mathrm{O}\right),\left(68 \mathrm{TeO}_{2}-5 \mathrm{Nb}_{2} \mathrm{O}_{5}-20 \mathrm{ZnO}-7 \mathrm{Na}_{2} \mathrm{O}\right)$ and $[(75-x)$ $\mathrm{TeO}_{2}-5 \mathrm{Nb}_{2} \mathrm{O}_{5}-20 \mathrm{ZnO}-x \mathrm{PbO}, x=7,18 \mathrm{~mol} \%$ ] were melted with reagent grade ingredients of $\mathrm{TeO}_{2}$ and pre-dried oxides. The batches were put into a gold crucible and heated at a temperature of $820-920^{\circ} \mathrm{C}$. The melt was allowed to cool to $750{ }^{\circ} \mathrm{C}$ and then cast in a graphite mould. Subsequently, the samples were transferred to an annealing furnace and kept at $300{ }^{\circ} \mathrm{C}$ for $2 \mathrm{~h}$. Then the furnace was switched off and allowed to cool. The densities, $\rho$, of the glass samples were measured by a helium pycnometer (AccuPyc 1330 Pycnometer) with an accuracy of $+0.03 \%$. The glass sample in powdered form of about $20 \mathrm{mg}$ was heated in a platinum pan at a heating rate of $10{ }^{\circ} \mathrm{C} / \mathrm{min}$ in the $30-750{ }^{\circ} \mathrm{C}$ temperature range to record DTA curves. From the glassy samples, prisms of dimension $30 \times 15 \times 15 \mathrm{~mm}^{3}$ were cut. The prisms were used to measure the linear refractive indices at wavelengths of $643.8,589 \cdot 3,546 \cdot 1,479.98$ and $435.8 \mathrm{~nm}$. 
To measure nonlinear refractive indices, flat samples with a thickness of $1 \mathrm{~mm}$ were prepared. Degenerated four-wave mixing (DFWM) was applied to measure $n_{2}$. Figure 1 shows experimental set up used. A Ti sapphire laser system delivering $150 \mathrm{fs}$ pulses of a wavelength of $800 \mathrm{~nm}$ was used. The pulse energies were in the range from 3-4 $\mu \mathrm{J}$ with a repetition rate of $10 \mathrm{~s}^{-1}$. Due to the small repetition rates and short duration of the pulses, thermo optical effects are negligible. DFWM set up used tuneable laser splitters; each of them consisting of a rotatory half-wave plate and a glan prism. This enables an easy adjustment of the intensities of the three pump beams. Two of the pump beams were sent through delay stages. The first served to adjust the temporal overlap of two of the pump beams, whereas the second delay stage was tuned to set the third pump beam to a delay $\Delta t$ in relation to a other two pulses. The three beams were focused onto the sample by a lens with a focal length of $12.5 \mathrm{~cm}$. The angle between the pump beams was $4^{\circ}$. All three beams had approximately the same intensity and were linearly polarized in the same direction. For each time delay, the measured signals were averaged over at least 30 laser pulses. In order to minimize the effect of pulse energy fluctuations, for each pulse, the DFWM signal was divided by a reference signal obtained by a reference detector measuring pulse energy. For a Kerr-like nonlinearity and negligible absorption in the sample at the respective wavelength, the maximum DFWM signal intensity, $I_{\mathrm{DFWM}}$, is given by (Samoc et al 1998) (with $I=$ intensity of the pump beams, $L=$ length of the sample):

$$
I_{\mathrm{DFWM}}=\mathrm{const} \cdot \frac{\left|\chi^{(3)}\right|}{n^{4}} \cdot L^{2} \cdot I^{3}=\mathrm{const}^{\prime} \cdot\left|n_{2}\right|^{2} \cdot L^{2} \cdot I^{3} .
$$

The signal intensity depends on $\left|n_{2}\right|^{2}$ and hence no statement on the sign of $n_{2}$ is possible. The signal intensity was referenced to fused silica; the $\left|n_{2}\right|$ values were calculated using (2)

$$
\begin{aligned}
\frac{\mid n_{2} \text { (sample) } \mid}{\mid n_{2} \text { (ref.) } \mid}= & \sqrt{\frac{I_{\mathrm{DFWM}(\text { sample })}}{I_{\mathrm{DFWM}(\text { ref. })}}} \frac{L \text { (ref.) }}{L \text { (sample) }} \\
& \times\left(\frac{1-R \text { (ref.) }}{1-R \text { (sample) }}\right)^{2} .
\end{aligned}
$$

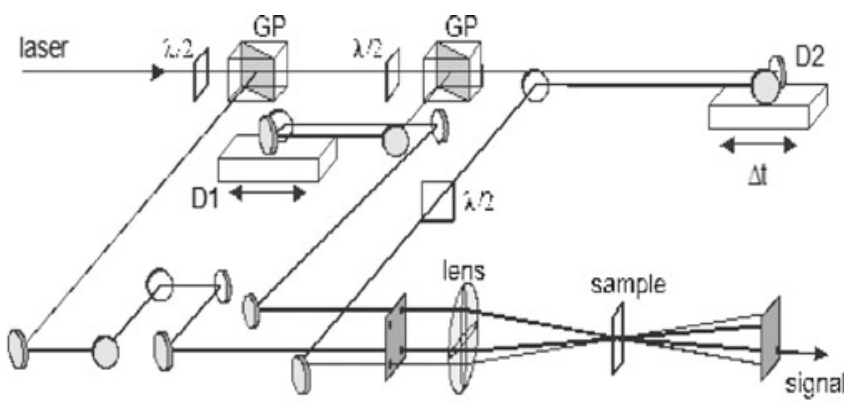

GP - Glan-polarizers

N2 - half-wave plates

Figure 1. Experimental set up for degenerate four-wave mixing (DFWM).
The last term in (8) introduces a correction of the reflection losses at the samples and reference surfaces (which are notably different for tellurite glass and fused silica). The reflectivity, $R$, was calculated from the linear refractive indices using Fresnel equation. The nonlinear refractive index, $n_{2}$, of fused silica was assumed to be $3 \cdot 10^{-16} \mathrm{~cm}^{2} / \mathrm{W}$ (Vijaya et al 2001). Vickers hardness $(H)$ at room temperature was measured by using Metkon (NH3) in air. The applied load was in the range 0.245 to $9.8 \mathrm{~N}$ and the time of loading was $10 \mathrm{~s}$. Measurements for each sample were conducted 5 times under the same measuring conditions. IR spectra were recorded in the range $900-4000 \mathrm{~cm}^{-1}$ using a Polytec M200 FTIR spectrometer. Abscissa accuracy is better than $\pm 5 \mathrm{~cm}^{-1}$; ordinate accuracy and $\% T$ repeatability are better than $\pm 0.2 \% T$.

\section{Results and discussion}

\subsection{Density and thermal characteristics}

Compositions, densities, molar volume, oxygen molar volume, oxygen packing density, glass transition temperature and softening temperature of the prepared glasses are summarized in table 1. Sample A with a composition of $85 \mathrm{TeO}_{2}-5 \mathrm{Nb}_{2} \mathrm{O}_{5}-5 \mathrm{ZnO}-5 \mathrm{Ag}_{2} \mathrm{O}$ has lowest value of density $\left(\rho=5.3744 \mathrm{~g} \cdot \mathrm{cm}^{-3}\right)$. Otherwise, sample $\mathrm{C}$ with composition, $57 \mathrm{TeO}_{2}-5 \mathrm{Nb}_{2} \mathrm{O}_{5}-20 \mathrm{ZnO}-18 \mathrm{PbO}$, has a highest value of density $\left(\rho=6.0731 \mathrm{~g} \cdot \mathrm{cm}^{-3}\right)$. But sample D with a composition of $68 \mathrm{TeO}_{2}-5 \mathrm{Nb}_{2} \mathrm{O}_{5}-20 \mathrm{ZnO}-7 \mathrm{Na}_{2} \mathrm{O}$ has lowest value of molar volume $\left(V=26.32 \mathrm{in}^{3}\right)$ and sample A has highest value of molar volume $\left(V=30.628 \mathrm{~cm}^{3}\right)$. The observed change of density of the present glasses may be attributed to atomic mass and change of interatomic spacing inside the prepared glass matrix. When a higher molecular weight is substituted by a lower molecular weight, it will result in increase in strong connectivity in the glass network. Moreover $\mathrm{Pb}^{2+}$ ions occupy interstitial positions in the glass network modifiers besides some $\mathrm{Nb}^{5+}$ ions existing as $\mathrm{NbO}_{4}$ tetrahedra which takes part as network formers, forming three-dimensional structural units of sample $\mathrm{C}$ leading to increasing density and consequently decreasing molar volume. From the density value and molar volume of the prepared glass, we can calculate the oxygen molar volume, $V_{\mathrm{O}}$, as follows (Ataf and Ashraf Chaudhry 2010);

$$
V_{\mathrm{O}}=\left(\frac{\sum x_{i} M_{i}}{\rho}\right)\left(\frac{1}{\sum x_{i} n_{i}}\right),
$$

where $x_{i}$ is the molar fraction of each component $i ; M_{i}$ the molecular weight and $n_{i}$ the number of oxygen atoms in each oxide. The value of $V_{\mathrm{O}}$ in the prepared samples lies between 14 to $14.951 \mathrm{~cm}^{3} \cdot \mathrm{mol}^{-1}$. Oxygen packing density (OPD) was estimated by using the following equation

$$
\mathrm{OPD}=\frac{1000 \times \rho \times \mathrm{O}_{i}}{M_{i}},
$$


Table 1. Density, $\rho$, molar volume, $V_{\mathrm{m}}$, oxygen molar volume, $V_{\mathrm{O}}$, oxygen packing density, glass transition temperature, $T_{\mathrm{g}}$ and softening temperature, $\Delta T_{\mathrm{S}}$ of prepared glasses.

\begin{tabular}{|c|c|c|c|c|c|c|c|c|c|c|}
\hline $\begin{array}{l}\text { Sample } \\
\text { name }\end{array}$ & & System co & position & & $\begin{array}{c}\rho \\
\left(\mathrm{g} \cdot \mathrm{cm}^{-3}\right)\end{array}$ & $\begin{array}{c}V_{\mathrm{m}} \\
\left(\mathrm{cm}^{3}\right)\end{array}$ & $\begin{array}{c}V_{\mathrm{O}} \\
\left(\mathrm{cm}^{3} \cdot \mathrm{mol}^{-1}\right)\end{array}$ & $\begin{array}{c}\text { OPD } \\
\left(\mathrm{g} \cdot \text { atom } 1^{-1}\right)\end{array}$ & $\begin{array}{c}T_{\mathrm{g}} \\
\left({ }^{\circ} \mathrm{C}\right)\end{array}$ & $\begin{array}{l}\Delta T_{\mathrm{S}} \\
\left({ }^{\circ} \mathrm{C}\right)\end{array}$ \\
\hline A & $85 \mathrm{TeO}_{2}$ & $5 \mathrm{Nb}_{2} \mathrm{O}_{5}$ & $5 \mathrm{ZnO}$ & $5 \mathrm{Ag}_{2} \mathrm{O}$ & $5 \cdot 3744$ & $30 \cdot 628$ & 14.94 & $66 \cdot 933$ & 350 & 403 \\
\hline B & $68 \mathrm{TeO}_{2}$ & $5 \mathrm{Nb}_{2} \mathrm{O}_{5}$ & $20 \mathrm{ZnO}$ & $7 \mathrm{PbO}$ & 5.6637 & $27 \cdot 141$ & 14.437 & $69 \cdot 267$ & 347 & 390 \\
\hline $\mathrm{C}$ & $57 \mathrm{TeO}_{2}$ & $5 \mathrm{Nb}_{2} \mathrm{O}_{5}$ & $20 \mathrm{ZnO}$ & $18 \mathrm{PbO}$ & 6.0731 & $26 \cdot 464$ & 14.951 & $66 \cdot 884$ & 344 & 389 \\
\hline $\mathrm{D}$ & $68 \mathrm{TeO}_{2}$ & $5 \mathrm{Nb}_{2} \mathrm{O}_{5}$ & $20 \mathrm{ZnO}$ & $7 \mathrm{Na}_{2} \mathrm{O}$ & 5.4116 & $26 \cdot 32$ & 14 & 71.429 & 326 & 382 \\
\hline
\end{tabular}

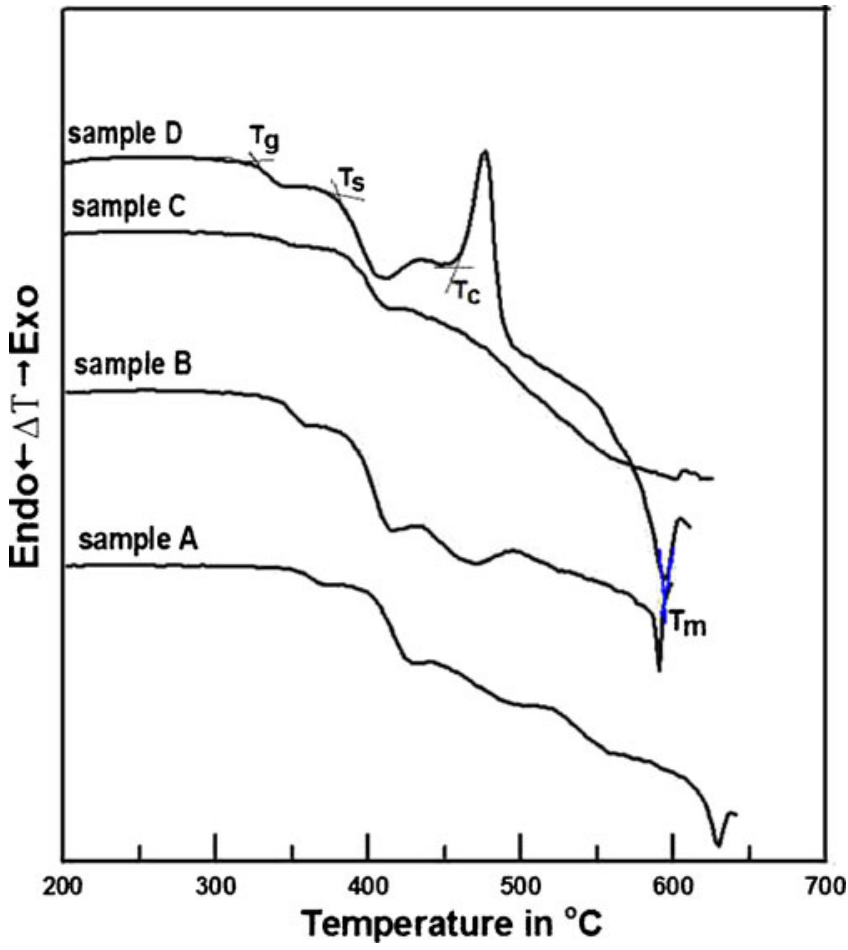

Figure 2. DTA curves of prepared glasses (sample A, $85 \mathrm{TeO}_{2}-$ $5 \mathrm{Nb}_{2} \mathrm{O}_{5}-5 \mathrm{ZnO}-5 \mathrm{Ag}_{2} \mathrm{O}$, sample $\mathrm{B}, \quad 68 \mathrm{TeO}_{2}-5 \mathrm{Nb}_{2} \mathrm{O}_{5}-20 \mathrm{ZnO} /$ $7 \mathrm{PbO}$, sample $\mathrm{C}, 57 \mathrm{TeO}_{2}-5 \mathrm{Nb}_{2} \mathrm{O}_{5}-20 \mathrm{ZnO}-18 \mathrm{PbO}$ and sample $\mathrm{D}$, $\left.68 \mathrm{TeO}_{2}-5 \mathrm{Nb}_{2} \mathrm{O}_{5}-20 \mathrm{ZnO}-7 \mathrm{Na}_{2} \mathrm{O}\right)$.

where $\mathrm{O}_{i}$ is number of oxygen atoms in the composition. The OPD value of prepared sample lies between 66.267 and $71.429 \mathrm{~g} \cdot$ atom.litre ${ }^{-1}$. The largest value of oxygen molar volume and smallest value of oxygen packing density have been observed at $18 \mathrm{~mol} \% \mathrm{PbO}$. This can be explained by the lower field intensity of $\mathrm{Pb}^{2+}$ ions $(0 \cdot 26-$ $0.27)$ compared with higher field intensity of $\mathrm{Te}^{4+}$ ions $(0.71)$ expanding the glass network and increasing the $V_{\mathrm{O}}$ value.

Thermal stability of the prepared glasses has been examined by measuring the differential thermal analysis (DTA) as has been shown in figure 2 . The exothermic peaks of crystallization do not appear in DTA curves of samples A, B and C. This indicated that sample A has very low tendency to crystallization and extremely high thermal stability, similar to samples B and C, however, sample D has thermal stability, $\Delta T=135^{\circ} \mathrm{C}$. So, these prepared glasses especially samples
A, B and C may be desirable for candidate optic preparation. Highest value of glass transition temperature $\left(T_{\mathrm{g}}=350{ }^{\circ} \mathrm{C}\right)$ was determined for sample A but sample $\mathrm{D}$ has lowest value of $T_{\mathrm{g}}=326{ }^{\circ} \mathrm{C}$. It is considered that these glasses of $\mathrm{TeO}_{4}$ polyhedra added with $\mathrm{Ag}_{2} \mathrm{O}$ attributed to the higher binding energy leads to increase in $T_{\mathrm{g}}$. The number of non-bridging oxygens increase with decreasing $\mathrm{Te}^{4+}$ former of the glass $68 \mathrm{TeO}_{2}-5 \mathrm{Nb}_{2} \mathrm{O}_{5}-20 \mathrm{ZnO}-7 \mathrm{Na}_{2} \mathrm{O}$. This leads to the glass network of sample $\mathrm{D}$ open which leads to decreasing glass transition temperature. The ratio of $\mathrm{Te}^{4+}$ former increases for sample A due to increasing bridging oxygen in the glass matrix. Consequently, the glass transition temperature, $T_{\mathrm{g}}$, value, for sample A was increased. We can conclude that the behaviour of glass transition temperature is strongly related to the ratio of $\mathrm{TeO}_{2}$ oxide in the constituent of the prepared glass.

\subsection{Refractive indices, nonlinear susceptibility and IR spectra}

The substitution of additional cations of $\mathrm{Ag}_{2} \mathrm{O}, \mathrm{Na}_{2} \mathrm{O}$ or $\mathrm{PbO}$ induces a structural variation from $\left(\mathrm{TeO}_{4}\right)^{4-}$ to $\left(\mathrm{TeO}_{3}\right)^{2-}$ entities as an intermediate asymmetric structure. This leads to change in the optical properties of prepared glasses. The Lorentz-Lorenz equation relates molar refraction to refractive indices and molar volume as done (Kordes 1939; Fajans and Kreidl 1948):

$$
\begin{aligned}
& n_{0}=\left(\frac{V_{\mathrm{m}}+2 R_{\mathrm{m}}}{V_{\mathrm{m}}-R_{\mathrm{m}}}\right)^{1 / 2}, \\
& \alpha=\left(\frac{3 M}{4 \pi N \rho}\right) \cdot\left(\frac{n_{0}^{2}-1}{n_{0}^{2}+2}\right),
\end{aligned}
$$

where $n_{0}$ is the linear refractive index, $R_{\mathrm{m}}$ the molar refraction, $V_{\mathrm{m}}$ the molar volume and $N$ the Avogadro's number. Linear refractive index measured at wavelengths of 435.8 , 479.98, 546.1 and $643.8 \mathrm{~nm}$ as well as the Abbe numbers calculated, polarizability, $\alpha$ (in $\AA^{3}$ ) and molar refraction, $R_{\mathrm{m}}\left(\right.$ in $\mathrm{cm}^{3} \mathrm{~mol}^{-1}$ ) are summarized in table 2 . The results show that highest values of refractive index were obtained when $\mathrm{Pb}^{2+}$ was incorporated into the tellurite glasses. It is observed that the glass $68 \mathrm{TeO}_{2}-5 \mathrm{Nb}_{2} \mathrm{O}_{5}-20 \mathrm{ZnO}-7 \mathrm{PbO}$ has highest value of refractive index, $n_{0}$, accompanied by highest value of electronic polarizability, $\alpha,\left(n_{0}=2.2123\right.$ at $435 \mathrm{~nm}$, 
$\alpha=5.77 \AA^{3}$ ). But a glass $68 \mathrm{TeO}_{2}-5 \mathrm{Nb}_{2} \mathrm{O}_{5}-20 \mathrm{ZnO}-7 \mathrm{Na}_{2} \mathrm{O}$ has smallest $n_{0}=2.1273$ at $435 \mathrm{~nm}$ and $\alpha=5.36 \AA^{3}$. Ions of greater mass, e.g. $\mathrm{Pb}^{2+}$, with double $s$-orbitals will have a low lying exciting configuration $\left(n s^{1}\right)\left(n p^{1}\right)$ due to the electron movement of the $s$ - to the non-occupied $p$-orbitals. Hence, the polarizability and refractive index increase with founding of $\mathrm{PbO}_{2}$ in the glasses matrix. According to the proposed theory on metallization of condensed matter (Herzfeld 1970; Burger et al 1995; Reddy et al 2001), the condition $\rho \cdot R_{\mathrm{m}} / M=1$ in the Lorentz-Lorenz equation, the refractive index becomes infinite which corresponds to the metallization of covalent solid materials, and two conditions for predicting the non-metallic $\left(\rho \cdot R_{\mathrm{m}} / M<1\right)$ and metallic ( $\rho$. $\left.R_{m} / M>1\right)$ materials. The metallization criterion, $M(n)$, is the difference from 1 as given below;

$$
M\left(n_{0}\right)=1-\frac{\rho \cdot R_{m}}{M} .
$$

The glasses reported here possess metallization criterion in the range 0.464 to 0.487 . Sample B has the smallest value of $M\left(n_{0}\right)=0.464$ but sample $\mathrm{D}$ has the largest value of $M\left(n_{0}\right)=0.487$ (column 2 in table 3 ). The small metallization criterion means that the width of both valence and conduction bands becomes large due to a narrow bandgap and increased tendency for metallization of the glasses (Himan et al 1994). The linear refractive index depends on the wavelength and was found as follow (Wample 1977):

$$
\frac{1}{n^{2}(E)-1}=\frac{E_{\mathrm{s}}}{E_{\mathrm{d}}}-\frac{E^{2}}{E_{\mathrm{s}} E_{\mathrm{d}}},
$$

where $E_{\mathrm{s}}$ is the so-called Sellmeier gap energy and $E_{\mathrm{d}}$ the dispersion energy. Figure 3 shows a plot of $1 /\left(n^{2}(w)-1\right)$ vs $E^{2}$ for all glasses studied. From the linear regression, values of $E_{\mathrm{s}}$ and $E_{\mathrm{d}}$ are obtained for each studied glass composition. As shown in table 3 , sample $\mathrm{D}$ has the smallest value of $E_{\mathrm{d}}(=19.78 \mathrm{eV})$ but sample $\mathrm{B}$ has the highest value $\left(E_{\mathrm{d}}=20.97 \mathrm{eV}\right)$. The decreasing of $E_{\mathrm{d}}$ values due to decrease of the covalent bond in the prepared glasses on incorporation of $\mathrm{Na}_{2} \mathrm{O}$ mol\% in glass matrix of sample $\mathrm{D}$ is seen and consequently a decrease in dispersion energies.

Figure 4 presents a typical DFWM measurement at a wavelength of $800 \mathrm{~nm}$ of a glass with the composition, $68 \mathrm{TeO}_{2} / 5 \mathrm{Nb}_{2} \mathrm{O}_{5} / 20 \mathrm{ZnO} / 7 \mathrm{PbO}$ (sample $\mathrm{B}$ ), with fused silica as a reference. The intensity of the signal of tellurite glass is about 300 times larger than that of fused silica.

The third order nonlinear susceptibility, $\chi^{(3)}$, depends on the nonlinear optical susceptibility as follows

$$
\chi^{(3)}\left(n_{0}\right)=\left[\frac{\left(n_{0}\right) \cdot\left(n_{2}\right)}{3 \pi}\right] \cdot 10^{-12} \text { esu, }
$$

where $n_{0}$ is the linear refractive indices of composition at $800 \mathrm{~nm}$ and the nonlinear refractive indices $\left|n_{2}\right|$ values of prepared glasses are in the range from 5.4 to $8 \cdot 1 \cdot 10^{-15} \mathrm{~cm}^{2} \cdot \mathrm{W}^{-1}$, which increase with increasing refractive indices. The largest values of nonlinear refractive indices $\left(n_{2}=8 \cdot 1 \cdot 10^{-15} \mathrm{~cm}^{2} \cdot \mathrm{W}^{-1}\right)$ and measured third order of nonlinear indices $\chi^{(3)}=17 \cdot 9 \cdot 10^{-13}$ esu were obtained for glass $B$ with the composition, $68 \mathrm{TeO}_{2}-5 \mathrm{Nb}_{2} \mathrm{O}_{5}-20 \mathrm{ZnO}-7 \mathrm{PbO}$, while the smallest values of $n_{2}=5 \cdot 4 \cdot 10^{-15} \mathrm{~cm}^{2} \cdot \mathrm{W}^{-1}$ and $\chi^{(3)}=11 \cdot 5 \cdot 10^{-13}$ esu were obtained for glass $\mathrm{D}$ with composition, $68 \mathrm{TeO}_{2}-5 \mathrm{Nb}_{2} \mathrm{O}_{5}-20 \mathrm{ZnO}-7 \mathrm{Na}_{2} \mathrm{O}$. The increasing of third order can be attributed to bridging oxygens that increase in the glass matrix and it is also due to virtual electron transitions from non-bonding $\mathrm{O}_{2 p} \pi$ orbital to the empty nonbonding orbital of $\mathrm{TeO}_{2}$. The optical bandgap relation to the nonlinear refractive index was shown by using the relation

$$
n_{\text {2cal }}=\beta /\left(E_{\mathrm{g}}\right)^{4},
$$

where $\beta=1.26 \times 10^{-9}\left(\mathrm{esu}(\mathrm{eV})^{4}\right)$. The calculated value of nonlinear refractive index is reported in table 3. They

Table 2. Refractive indices, Abbe number, molar refraction, $R_{\mathrm{m}}$, electronic polarizability, $\alpha_{\mathrm{m}}$, of glasses studied.

\begin{tabular}{llllllllll}
\hline $\begin{array}{l}\text { Sample } \\
\text { name }\end{array}$ & $435 \mathrm{~nm}$ & $479 \mathrm{~nm}$ & $546 \mathrm{~nm}$ & $587 \mathrm{~nm}$ & $643 \mathrm{~nm}$ & $\begin{array}{c}\text { Abbe } \\
\text { number }\end{array}$ & $\begin{array}{c}\text { Vickers } \\
\text { hardness }(\mathrm{GPa})\end{array}$ & $\begin{array}{c}R_{\mathrm{m}} \\
\left(\mathrm{cm}^{3} \mathrm{~mol}^{-1}\right)\end{array}$ & $\alpha_{\mathrm{m}}\left(\AA^{3}\right)$ \\
\hline A & $2 \cdot 1684$ & $2 \cdot 1355$ & $2 \cdot 1041$ & $2 \cdot 091$ & $2 \cdot 077$ & $18 \cdot 9$ & $3 \cdot 447$ & $16 \cdot 08$ & $6 \cdot 38$ \\
B & $2 \cdot 2123$ & $2 \cdot 1764$ & $2 \cdot 1425$ & $2 \cdot 128$ & $2 \cdot 1132$ & $17 \cdot 7$ & $3 \cdot 225$ & $14 \cdot 55$ & $5 \cdot 77$ \\
C & $2 \cdot 2118$ & $2 \cdot 175$ & $2 \cdot 1403$ & $2 \cdot 1255$ & $2 \cdot 1105$ & $18 \cdot 1$ & $3 \cdot 116$ & $14 \cdot 161$ & $5 \cdot 62$ \\
D & $2 \cdot 1273$ & $2 \cdot 0958$ & $2 \cdot 0657$ & $2 \cdot 053$ & $2 \cdot 0398$ & 19 & $2 \cdot 91$ & 13.5 & $5 \cdot 36$ \\
\hline
\end{tabular}

Table 3. Metallization, $M\left(n_{0}\right)$, energy gap, $E_{\mathrm{g}}$, Sellmeier energy gap, $E_{\mathrm{s}}$, dispersion energy, $E_{\mathrm{d}}$, nonlinear refractive indices, $n_{2}$, calculated nonlinear refractive index, $n_{2 \text { cal }}$ and third order nonlinear susceptibilities $\chi^{(3)}$ of studied glasses.

\begin{tabular}{lccccccc}
\hline $\begin{array}{l}\text { Sample } \\
\text { name }\end{array}$ & $\begin{array}{c}\text { Metallization } \\
\text { criterion }\end{array}$ & $E_{\mathrm{g}}(\mathrm{eV})$ & $E_{\mathrm{S}}(\mathrm{eV})$ & $E_{\mathrm{d}}(\mathrm{eV})$ & $n_{2}\left(10^{-15} \mathrm{~cm}^{2} / \mathrm{W}\right)$ & $n_{2 \mathrm{cal}}\left(10^{-12} \mathrm{esu}\right)$ & $\chi^{(3)}\left(10^{-13} \mathrm{esu}\right)$ \\
\hline $\mathrm{A}$ & 0.475 & 4.007 & $6 \cdot 76$ & 20.6 & 7.9 & 4.885 & $17 \cdot 1$ \\
$\mathrm{~B}$ & 0.464 & $2 \cdot 2083$ & 6.61 & 20.97 & $8 \cdot 1$ & $6 \cdot 126$ & 17.9 \\
$\mathrm{C}$ & 0.465 & 3.79 & 6.54 & 20.65 & $7 \cdot 8$ & $6 \cdot 11$ & $17 \cdot 2$ \\
$\mathrm{D}$ & 0.487 & 4.227 & 6.8 & 19.78 & 5.4 & 3.946 & 11.5 \\
\hline
\end{tabular}


are in good agreement with the data corresponding between experimental and calculated $n_{2}$ values. The third order nonlinear optical susceptibility, $\chi^{(3)}$, is inversely related to mean excitation energy, $E_{\mathrm{g}}$,

$$
\chi^{(3)}=\frac{C\left(n_{0}^{2}+2\right)\left(n_{0}^{2}-1\right) E_{\mathrm{d}}}{576 \pi^{2} N_{\mathrm{b}} E_{\mathrm{g}}},
$$

where $N_{\mathrm{b}}$ is the cationic bulk concentration of the glass and $C$ is a constant. Sample B has higher value of the third order nonlinear optical susceptibility with lowest value of optical energy gap. The calculated values of energy gap band for samples A, B, C and D are 4.007, 2.082, 3.79 and $4.227 \mathrm{eV}$, respectively. It is well known that tellurite glasses follow the pattern of crystalline $\alpha-\mathrm{TeO}_{2}$ which are formed

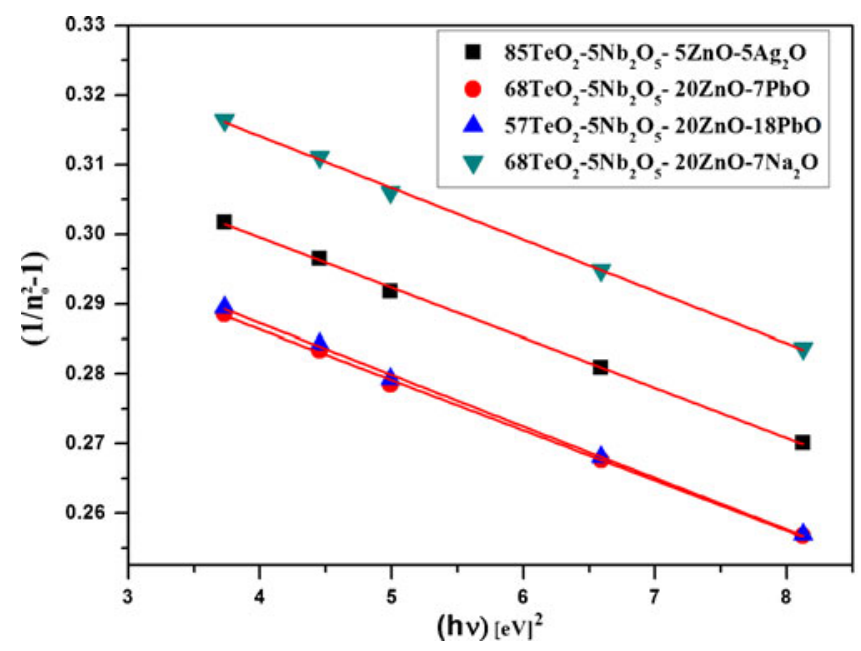

Figure 3. Dependency of refractive indices as a function of photon energy (illustrated as $1 /\left(n^{2}-1\right)$ vs $\left.(h v)^{2}\right)$ in prepared glasses.

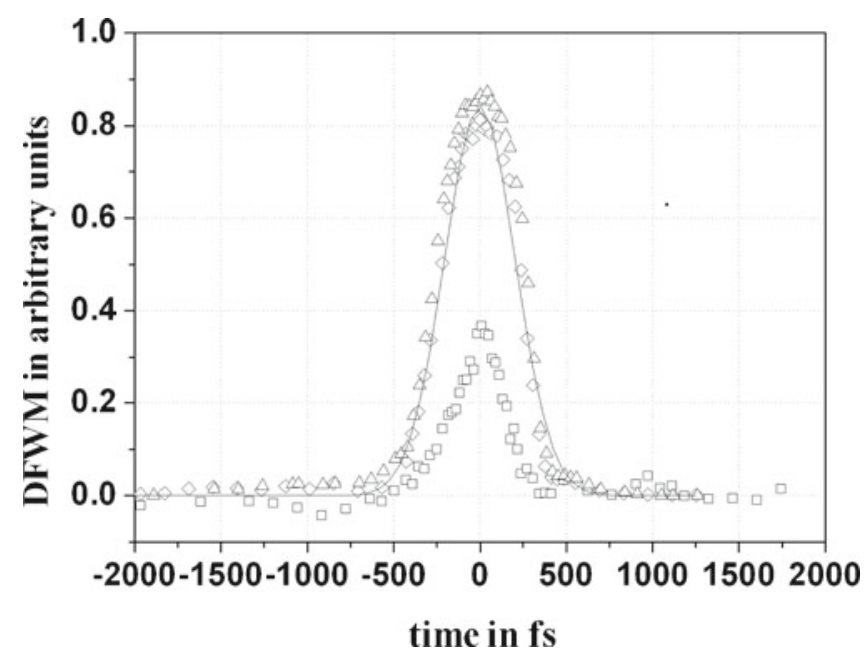

Figure 4. DFWM signal of sample $\left(\square 68 \mathrm{TeO}_{2} / 5 \mathrm{Nb}_{2} \mathrm{O}_{5} / 20 \mathrm{ZnO} /\right.$ $7 \mathrm{PbO}$ ) and compared to signal of fused silica reference sample at $800 \mathrm{~nm}(\Delta$, signal of fused silica is multiplied by a factor of 100 for better visibility). by $\mathrm{TeO}_{4}$ group as trigonal bipramids (tbp), such structural units can progressively form $\mathrm{TeO}_{3+1}$ and non-bridging oxygens are created due to the incorporation of modifier ions (Sekiya et al 1994). It can be concluded that $\mathrm{TeO}_{4}$ tbp with low $E_{\mathrm{g}}$ will contribute more to optical nonlinearity than $\mathrm{TeO}_{3}$ tp with high $E_{\mathrm{g}}$ in the glass $\mathrm{TeO}_{2}-\mathrm{Nb}_{2} \mathrm{O}_{5}-\mathrm{ZnO}$. Berthereau et al (1996) reported that the energy gap, $E_{\mathrm{g}}$, between highest occupied molecular orbital (HOMO) and lowest unoccupied molecular orbital (LUMO) in $\mathrm{TeO}_{4}$ tbp is $10.2 \mathrm{eV}$ and that in $\mathrm{TeO}_{3}$ tp is $12 \cdot 1 \mathrm{eV}$. Fargin et al (1996) confirmed that the mean polarizability for $\mathrm{TeO}_{4}$ tbp is about $20 \%$ higher than that for the $\mathrm{TeO}_{3}$ tp. $\mathrm{PbO}$ behaves both as a network former and as network modifier in glasses. When $\mathrm{PbO}$ acts as a network former, $\mathrm{Pb}$ atoms take up four coordinating positions and the lead oxygen polyhedron can be represented as $\left[\mathrm{PbO}_{4 / 2}\right]^{2-}$. Formation of $\left[\mathrm{PbO}_{4 / 2}\right]^{2-}$ requires additional oxygen atoms and carry lone pairs in bounded states with high polarizability. Therefore, in the system of glasses investigated here $68 \mathrm{TeO}_{2}-5 \mathrm{Nb}_{2} \mathrm{O}_{5}-20 \mathrm{ZnO}-$ $7 \mathrm{PbO}$ will be those showing higher number of value of $\mathrm{TeO}_{4}$ tbp due to smallest value of energy gap and highest value of nonlinear susceptibility. When increase of $\mathrm{PbO}$ content leads to $\mathrm{TeO}_{4}$ tbp into $\mathrm{TeO}_{3}$ tp which decreases the refractive index and nonlinear susceptibility.

IR spectra of prepared glasses have been shown in figure 5 . This figure reveals broad, strong and weak absorption bands in the investigated range of wave numbers $1200-400 \mathrm{~cm}^{-1}$, the precision of recording band maxima is $+2 \mathrm{~cm}^{-1}$. Tomokatsu et al (2010) studied Raman and infrared spectra of $\mathrm{TeO}_{2}-\mathrm{Nb}_{2} \mathrm{O}_{5}-\mathrm{ZnO}$ glass. They found that the band at

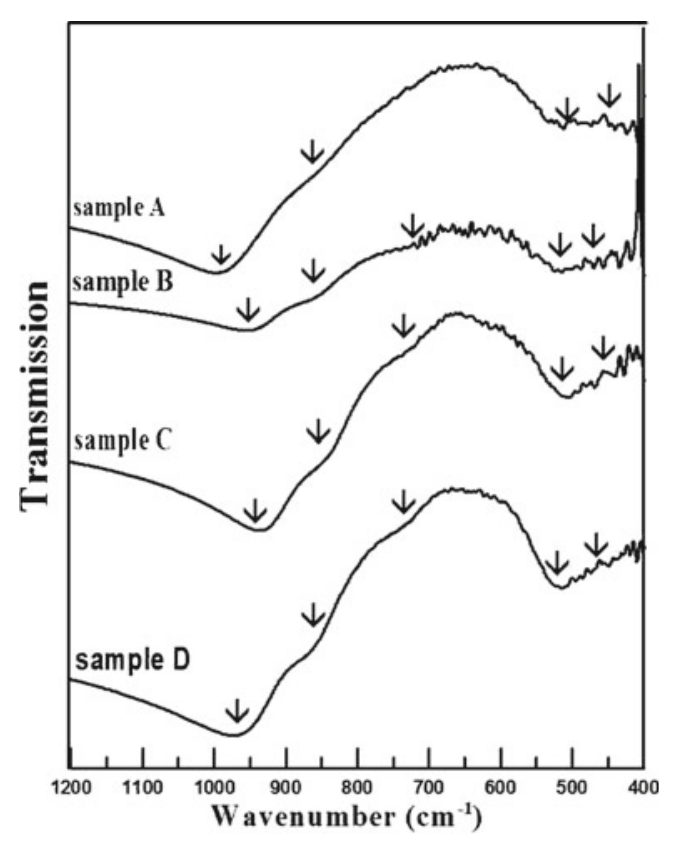

Figure 5. Infrared spectra of prepared glass (sample A, $85 \mathrm{TeO}_{2}-5 \mathrm{Nb}_{2} \mathrm{O}_{5}-5 \mathrm{ZnO}-5 \mathrm{Ag}_{2} \mathrm{O}$, sample $\mathrm{B}, 68 \mathrm{TeO}_{2}-5 \mathrm{Nb}_{2} \mathrm{O}_{5}-$ $20 \mathrm{ZnO} / 7 \mathrm{PbO}$, sample $\mathrm{C}, 57 \mathrm{TeO}_{2}-5 \mathrm{Nb}_{2} \mathrm{O}_{5}-20 \mathrm{ZnO}-18 \mathrm{PbO}$ and sample $\left.\mathrm{D}, 68 \mathrm{TeO}_{2}-5 \mathrm{Nb}_{2} \mathrm{O}_{5}-20 \mathrm{ZnO}-7 \mathrm{Na}_{2} \mathrm{O}\right)$. 
$190-230 \mathrm{~cm}^{-1}$ was attributed to the vibration of $\mathrm{Nb}-\mathrm{O}$ in $\mathrm{NbO}_{6}$ octahedra, and that at $440 \mathrm{~cm}^{-1}$ was due to the symmetric stretching of the $\mathrm{Te}_{\mathrm{eq}}-\mathrm{O}_{\mathrm{ax}}-\mathrm{Te}$ band. The stretching bond of tellurium and axial oxygen $\left(\mathrm{Te}-\mathrm{O}_{\mathrm{ax}}\right)$ in $\mathrm{TeO}_{4}$ trigonal bipyramids (tbp) at $657-663 \mathrm{~cm}^{-1}$, and the stretching band in $\mathrm{TeO}_{3}$ trigonal pyramids (tp) occurs at $732 \mathrm{~cm}^{-1}$. So, the band which appeared at $440 \mathrm{~cm}^{-1}$ in prepared glasses are due to the symmetric and bending vibration if $\mathrm{Te}_{\mathrm{eq}}-\mathrm{O}_{\mathrm{ax}}-\mathrm{Te}$ linkages are connected with $\mathrm{TeO}_{4}$ units. The first overtone of these peaks are observed at around 950-1001 $\mathrm{cm}^{-1}$. The shoulder band appears at 748, 732 and $756 \mathrm{~cm}^{-1}$ in samples $\mathrm{B}, \mathrm{C}$ and $\mathrm{D}$, respectively; this is attributed to $\mathrm{TeO}_{3}$ tp. When the $\mathrm{PbO}$ molar increases substituting $\mathrm{TeO}_{2}$ in sample $\mathrm{C}$ the bands shift towards lower frequency. This shift may be attributed to the $\mathrm{Pb}^{2+}$ ions incorporation as network modifiers which form bridging oxygen in $\mathrm{Te}-\mathrm{Pb}^{2+}-\mathrm{Te}$ linkages. The band at $880 \mathrm{~cm}^{-1}$ is attributed to $\mathrm{NbO}_{4}$ tetrahedra groups which will contribute to restore bridging bonds and will increase the number of $\left[\mathrm{TeO}_{4}\right]$ groups.

\subsection{Vickers hardness}

From deformation fracture patterns in Vickers indentation tests, the values of Vickers hardness, $H_{\mathrm{V}}$, for prepared glasses were calculated using (7) (Tadashi et al 2001),

$$
H_{V}=\frac{P}{\alpha_{0} d^{2}},
$$

where $P$ is the applied load, $d$ a characteristic indentation diagonal and $\alpha_{0}$ the indenter constant $\left(\alpha_{0}=2 \cdot 15\right)$ in the present experiment which used a diamond pyramid indenter. The calculated values of Vickers hardness at room temperature are shown in table 2. It is seen that sample B has a highest value $\left(H_{\mathrm{V}}=3.447 \mathrm{GPa}\right)$ but sample $D$ has a lowest value $(H=2.91 \mathrm{GPa})$. As expected, the Vickers hardness increases with increasing cross link density and strength chemical bonds of the network. By addition, the

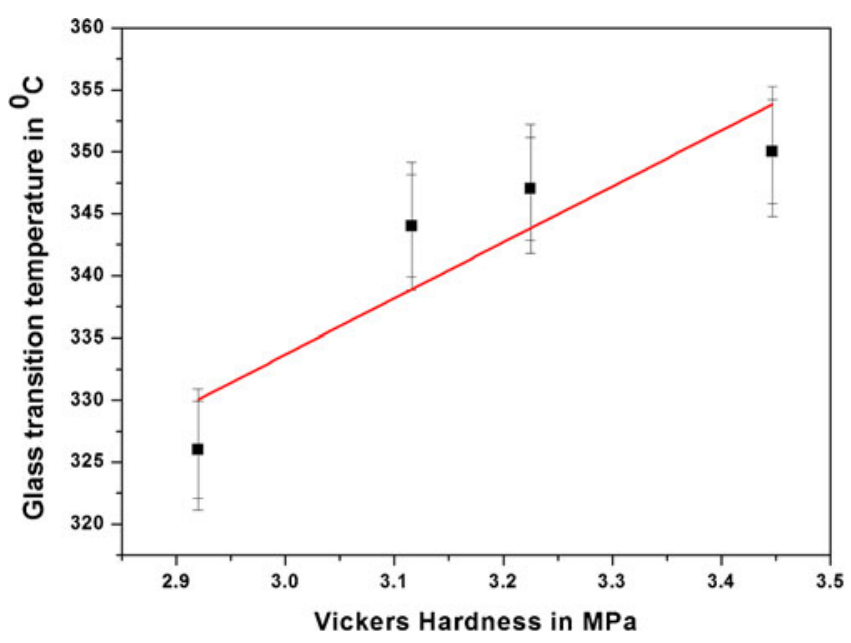

Figure 6. Vickers hardness vs glass transition of prepared glasses (line is guide to eye). bridging oxygen ion produces rigidity of the glass. Since the Vickers hardness increases with increasing $\mathrm{PbO}$ content in the prepared glass matrix, we know that $\mathrm{Na}_{2} \mathrm{O}$ has a packing density lower than that of $\mathrm{TeO}_{2}$ and this leads to decreasing of Vickers hardness in prepared glasses, when $\mathrm{TeO}_{2}$ is replaced by $\mathrm{Na}_{2} \mathrm{O}$. The values of Vickers hardness for the prepared glasses are higher than that of $70 \mathrm{TeO}_{2}-15 \mathrm{ZnO}-$ $15 \mathrm{Na}_{2} \mathrm{O}$ and $70 \mathrm{TeO}_{2}-20 \mathrm{WO}_{3}-10 \mathrm{~K}_{2} \mathrm{O}$ glasses (Watanabe et al 2001). Figure 6 shows the relation between glass transition temperature and Vickers hardness of prepared glasses. This means that, the weakening of the glass structure reduces the hardness hence a decrease in $T_{\mathrm{g}}$ and vice versa. The glass transition temperature of an oxide glass increases with cross link density of the network, with increasing strength of the chemical bonds and with the packing density of the oxide network.

\section{Conclusions}

The molar polarizability, dispersion energy and third order of nonlinear susceptibility have been estimated on the basis of measurement of the linear refractive indices, $n_{0}$. The values of glass transition temperature of prepared glasses increase in the order of modifier as follow: $\mathrm{Ag}_{2} \mathrm{O}>\mathrm{PbO}>\mathrm{Na}_{2} \mathrm{O}$. The value of Vickers hardness of the prepared glasses increase in the same way as glass transition temperature in the order of $\mathrm{Ag}_{2} \mathrm{O}>\mathrm{PbO}>\mathrm{Na}_{2} \mathrm{O}$. The sample within composition, $68 \mathrm{TeO}_{2} / 5 \mathrm{Nb}_{2} \mathrm{O}_{5} / 20 \mathrm{ZnO} / 7 \mathrm{PbO}$, in mole $\%$ has largest value of third order of nonlinear indices, extremely high thermal stability, very low tendency to crystallization and smallest value of energy gap $\left(E_{\mathrm{g}}=2 \cdot 2082 \mathrm{eV}\right)$. Finally the value of refractive indices changes in the order, $\mathrm{PbO}>\mathrm{Ag}_{2} \mathrm{O}>\mathrm{Na}_{2} \mathrm{O}$.

\section{Acknowledgements}

This work was supported by a Grant of King Abdulaziz City for Science and Technology (Code Number: 10-ADV116007), King of Saudi Arabia.

\section{References}

Ataf M and Ashraf Chaudhry M 2010 J. Mod. Phys. 1201

Berthereau A, Fargin E and Villezusanne A 1996 J. Solid State Chem. 126143

Burger H, Vogel W and Kozhukharov V 1995 Infrared Phys. 25395 Fajans K and Kreidl N 1948 J. Am. Ceram. Soc. 31105

Fargin E, Berthereau A and Cardinal T 1996 J. Non-Cryst. Solids $20396 . S$

Herzfeld K 1970 Phys. Rev. B2 2045

Himan Y, Osaka A, Nanba T and Miura Y 1994 J. Non-Cryst. Solids 177164

Hoppe U, Yousef E, Rüssel C, Neuefeind J and Hannon A C 2002 Solid State Commun. 123273

Hoppe U, Yousef E, Rüssel C, Neuefeind J and Hannon A C 2004 J. Phys.: Condens. Matter 161645

Kim S H and Yoko T 1995 J. Am. Ceram. Soc. 781061 
Komatsu T, Luyer Y L and Olazcuage R 1994 Mater. Res. Bull. 29 933

Kordes 1939 Z. Anorg. Allg. Chem. 2411

Lin J, Huang W, Sun Z, Ray C S and Day D E 2004 J. Non-Cryst. Solids 336189

Narayanan R A and Zwanziger J W 2003 J. Non-Cryst. Solids 316 273

Reddy R R, Nazeer Ahmed Y, Abdul Azeem P, Rama Gopal K and Rao T V R 2001 J. Non-Cryst. Solids 286 169

Samoc M, Samoc A, Luther B, Bao Z, Yu L P, Hesieh B and Scherf U 1998 J. Opt. Soc. Am. B15 817

Sekiya T, Mochida N and Othsuka A 1994 J. Non-Cryst. Solids 168 106
Tadashi M, Toshio W, Yasuhiko B and Takayuki K $2001 \mathrm{~J}$. Am. Ceram. Soc. 842401

Tomokatsu H, Masahiko H, Masayuki N and Philippe T 2010 Opt. Mater. 32448

Vijaya Prakash G, Narayana Rao D and Bhatnagar A K 2001 J. Solid State Commun. 11939

Wample S H 1977 J. Chem. Phys. 672151

Watanabe T, Benino Y and Komatsu T 2001 J. Non-Cryst. Solids 286141

Yousef E, Hotzel M and Rüssel C 2004 J. Non-Cryst. Solids 34282

Yousef E, Hotzel M and Rüssel C 2007 J. Non-Cryst. Solids 353 333

Yousef E, Horzel M and Russel C 2008 J. Non-Cryst. Solids 354 4675 